\title{
Low-Density Polyethylene Film Biodegradation Potential by Fungal Species from Thailand
}

\author{
Sarunpron Khruengsai ${ }^{1}$, Teerapong Sripahco ${ }^{1}$ and Patcharee Pripdeevech ${ }^{1,2, *}$ \\ 1 School of Science, Mae Fah Luang University, Chiang Rai 57100, Thailand; \\ 6171102001@lamduan.mfu.ac.th (S.K.); 6351102001@lamduan.mfu.ac.th (T.S.) \\ 2 Center of Chemical Innovation for Sustainability (CIS), Mae Fah Luang University, \\ Chiang Rai 57100, Thailand \\ * Correspondence: patcharee.pri@mfu.ac.th
}

Citation: Khruengsai, S.; Sripahco, T.; Pripdeevech, P. Low-Density Polyethylene Film Biodegradation Potential by Fungal Species from Thailand. J. Fungi 2021, 7, 594. https://doi.org/10.3390/jof7080594

Academic Editor: Craig Faulds

Received: 27 June 2021

Accepted: 21 July 2021

Published: 23 July 2021

Publisher's Note: MDPI stays neutral with regard to jurisdictional claims in published maps and institutional affiliations.

Copyright: (c) 2021 by the authors. Licensee MDPI, Basel, Switzerland. This article is an open access article distributed under the terms and conditions of the Creative Commons Attribution (CC BY) license (https:// creativecommons.org/licenses/by/ $4.0 /)$.

\begin{abstract}
Accumulated plastic waste in the environment is a serious problem that poses an ecological threat. Plastic waste has been reduced by initiating and applying different alternative methods from several perspectives, including fungal treatment. Biodegradation of 30 fungi from Thailand were screened in mineral salt medium agar containing low-density polyethylene (LDPE) films. Diaporthe italiana, Thyrostroma jaczewskii, Collectotrichum fructicola, and Stagonosporopsis citrulli were found to grow significantly by culturing with LDPE film as the only sole carbon source compared to those obtained from Aspergillus niger. These fungi were further cultured in mineral salt medium broth containing LDPE film as the sole carbon source for 90 days. The biodegradation ability of these fungi was evaluated from the amount of $\mathrm{CO}_{2}$ and enzyme production. Different amounts of $\mathrm{CO}_{2}$ were released from D. italiana, T. jaczewskii, C. fructicola, S. citrulli, and A. niger culturing with LDPE film, ranging from 0.45 to $1.45,0.36$ to $1.22,0.45$ to $1.45,0.33$ to 1.26 , and 0.37 to $1.27 \mathrm{~g} / \mathrm{L}$, respectively. These fungi were able to secrete a large amount of laccase enzyme compared to manganese peroxidase, and lignin peroxidase enzymes detected under the same conditions. The degradation of LDPE films by culturing with these fungi was further determined. LDPE films cultured with D. italiana, T. jaczewskii, C. fructicola, S. citrulli, and A. niger showed weight loss of $43.90 \%, 46.34 \%, 48.78 \%, 45.12 \%$, and $28.78 \%$, respectively. The tensile strength of LDPE films cultured with D. italiana, T. jaczewskii, C. fructicola, S. citrulli, and A. niger also reduced significantly by 1.56, 1.78, 0.43, 1.86, and 3.34 MPa, respectively. The results from Fourier transform infrared spectroscopy (FTIR) reveal an increasing carbonyl index in LDPE films culturing with these fungi, especially C. fructicola. Analysis of LDPE films using scanning electron microscopy (SEM) confirmed the biodegradation by the presence of morphological changes such as cracks, scions, and holes on the surface of the film. The volatile organic compounds (VOCs) emitted from LDPE films cultured with these fungi were analyzed by gas chromatography-mass spectrometry (GC-MS). VOCs such as 1,3-dimethoxy-benzene, 1,3-dimethoxy-5-(1-methylethyl)benzene, and 1,1-dimethoxy-decane were detected among these fungi. Overall, these fungi have the ability to break down and consume the LDPE film. The fungus $C$. fructicola is a promising resource for the biodegradation of LDPE which may be further applied in plastic degradation systems based on fungi.
\end{abstract}

Keywords: biodegradation; LDPE film; fungi; Fourier transform infrared spectroscopy (FTIR); scanning electron microscopy (SEM); gas chromatography-mass spectrometry (GC-MS)

\section{Introduction}

A trillion tons of plastic materials are produced around the world each year at a rate of $12 \%$ [1,2]. Thailand is one of the major countries that produces plastic materials in Southeast Asia, with a total production of around 27.8 million tons in the year 2020 [3]. LDPE is a long chain polyethylene and is known as one of the most widely used plastic materials worldwide [4,5]. It has been widely produced in the form of plastic bags for 
packaging materials due to its effectiveness and versatile properties, such as being cheap, durable, light weight, energy efficient, and easy to produce [6,7]. Plastic bags are evaluated as one of the major plastic wastes causing global environmental pollution due to their lightness, high tensile strength, and resistance to water and microbial attacks $[8,9]$. These plastic bags are generally released in the environment by dumping into landfills, rivers, and oceans [10]. In dumping areas, terrestrial animals usually consume plastic bag wastes along with foodstuffs, which disrupts their digestive systems, resulting in the deaths of millions of animals $[9,11,12]$.

Accumulated plastic bag wastes are generally degraded by physical, chemical, and photo-degradation processes [2,4]. However, these processes are very expensive, and release pollutant organic compounds and toxic irritant products into the environment, such as furans and dioxins [4]. The toxic compounds result in soil infertility, preventing degradation of normal substances, and depletion of underground water sources $[13,14]$. Recently, biodegradation by microorganisms has been reported to degrade plastic bag wastes through anaerobic processes in soil and composts, producing carbon dioxide, water, and methane $[15,16]$. Therefore, biodegradation is considered as an eco-friendly process for the removal of plastic bags which may be applied as an alternative method for plastic waste management.

Biodegradation is known as the decomposition of plastics by using microbial activity involving four steps: biodeterioration, depolymerization, assimilation, and mineralization $[17,18]$. The biodegradation rate of microorganisms is dependent on various factors, such as substrates, environment, temperature, and the molecular weight of the plastic material [12,17-19]. Their rates can be increased through various reactions such as abiotic hydrolysis, photo-oxidation, and physical disintegration [20]. Various fungal genera have been reported previously in the biodegradation of plastics, such as Gliocladium, Cunninghamella, Penicillium, Aspergillus, Fusarium, Mucor, and Mortierella [21-23]. In addition, many filamentous fungi including A. niger, Aspergillus terreus, Aureobasidium pullulans, Paecilomyces varioti, Penicillium funiculosum, Penicillium ochrochloron, Scopulariopsis brevicaulis, and Trichoderma viride were reported to have LDPE-degrading abilities [24]. The ability of fungi in the biodegradation of plastics was enhanced by producing special intracellular and extracellular enzymes for degrading polymers into small oligomers, dimers, and monomers [4,14]. These products are used as carbon sources for fungi growth and are converted into water, carbon dioxide, or methane [25]. Thus, the discovery of the biodiversity and occurrence of fungi with the potential to effectively biodegrade plastics has been a challenge for researchers.

Recently, the biodiversity of more than 500 species from both macro- and microfungi in Thailand was reported [26]. These species were discovered as microfungal plant pathogens, saprobes, endophytes, and epitypes [27]. Many thousands of strains of fungi from Thailand have been isolated and studied over the past few years [28]. Most of them have never been explored for their biodegradation potential. Accordingly, the obtained species of Thai mycobiota may be good candidates for the discovery of fungi for degrading plastics. Therefore, this study presents the LDPE biodegradation potential of fungal species from Thailand. The study also focuses on the biodegradation efficiency evaluated by FTIR, SEM, and GC-MS. The production of $\mathrm{CO}_{2}$ and enzymes after incubation was also determined.

\section{Materials and Methods}

\subsection{Fungal Strains}

Thirty fungal species were selected for this study, including Ophiosimulans tanaceti, Populacrescentia foricesenensis, Embarria clematidis, Sclerostagonospora lathyri, Pseudomassariosphaeria bromicola, Nodulosphaeria multiseptata, Vagicola chlamydospore, Halobyssothecium obiones, Paraepicoccum amazonense, Poaceascoma halophila, Pestalotiopsis microspore, Muyocopron heveae, Muyocopron dipterocarpi, C. fructicola, Collectotrichum pandanicola, Alternaria burnsii, Setoseptoria arundelensis, Cytospora centravillosa, D. italiana, Coniella vitis, Septome- 
lanconiella thailandica, Murilentithecium lonicerae, Phragmocamarosporium hederae, Keissleriella caraganae, Neomollisia gelatinosa, T. jaczewskii, Tamsiniella labiosa, Diaporthe rumicicola, Epicoccum pseudokeratinophilum, and S. citrulli. These strains were obtained from the culture collection of the Institute of Excellence in Fungal Research, Mae Fah Luang University, Thailand. The reference fungal strain used in this study was A. niger ATCC 10254, which was acquired from the culture collection of the Thailand Institute of Scientific and Technological Research, Bangkok, Thailand.

\subsection{Preparation of LDPE Film}

White and amorphous LDPE microplastic granules, $5 \mathrm{~mm}$ nominal size, (SigmaAldrich, Singapore) were used in this study. The LDPE film was prepared according to a modified method [29]. The $0.12 \mathrm{~mm}$ polymeric film was prepared by melting $0.2 \mathrm{~g}$ of LDPE polymer between aluminum foil in a hydraulic press (Carver, Wabash, IN, USA) at a temperature of $180^{\circ} \mathrm{C}$ and under $55.3 \mathrm{kgf} / \mathrm{cm}^{2}$ of pressure for $5 \mathrm{~min}$. The obtained films were cooled at room temperature.

\subsection{Screening of Potential Fungi for LDPE Film Degradation}

All fungal strains described above were screened for their ability to degrade LDPE films. The biodegradation test was performed in mineral salt medium broth containing LDPE film as the only sole carbon source [24]. The mineral salt medium broth containing $3 \mathrm{~g}$ $\mathrm{NH}_{4} \mathrm{NO}_{3}, 5 \mathrm{~g} \mathrm{~K}_{2} \mathrm{HPO}_{4}, 1 \mathrm{~g} \mathrm{NaCl}, 0.2 \mathrm{~g} \mathrm{MgSO} \cdot 7 \mathrm{H}_{2} \mathrm{O}$, and $1000 \mathrm{~mL}$ of deionized water was prepared following the study of Brunner et al. [30]. All chemicals are purchased from SigmaAldrich (Singapore). The medium contained the nutrients including nitrogen, phosphorus, sulfur, potassium, magnesium, sodium, and chlorine. A LDPE film $(1.0 \mathrm{~cm} \times 4.0 \mathrm{~cm})$ was placed into $250 \mathrm{~mL}$ of mineral salt medium broth in a $1000 \mathrm{~mL}$ Erlenmeyer flask prior to the inoculation of five agar plugs ( $5 \mathrm{~mm}$ diameter, 7 days old) of each strain. All solution flasks were stored at $\mathrm{pH} 7.0 \pm 0.2$. Fungal cultures were incubated at room temperature $\left(27.0 \pm 2.0^{\circ} \mathrm{C}\right)$ for 30 days under static conditions. The fungus $A$. niger was used as the control to confirm the degradation of LDPE film. After 30 days, fungal mycelium was filtered and vacuum dried for $24 \mathrm{~h}$. Mycelium dry weight obtained from each fungus was measured by digital weighing balance.

\subsection{Culturing Condition}

LDPE films were placed in mineral salt medium broth with agar plugs of potential fungi, as described above. The cultures were incubated at room temperature $\left(27.0 \pm 2.0^{\circ} \mathrm{C}\right)$ under static conditions for a duration of 30,60, and 90 days. The fungus $A$. niger (control) was tested as a basis for comparison.

\subsection{Screening of Enzymes Production}

The enzyme activity of potential fungi cultured with LDPE film after 30, 60, and 90 days of incubation was investigated following the study of Ameen et al. [31]. After the incubation period, the culture supernatant was separated from fungal culture and the obtained filtrates were tested for their enzyme activity, including laccase, manganese peroxidase, and lignin peroxidase. All chemicals were obtained from Sigma Chemical Co., St. Louis, MO, USA. Enzymic activity of laccase was determined at $420 \mathrm{~nm}$ via the oxidation of 2,2-azino-bis-3-ethyl-benzthiazoline-6-sulfonic acid (ABTS). Culture supernatant (50 $\mu \mathrm{L})$ was mixed with $0.1 \mathrm{mM}$ ABTS and $100 \mathrm{mM}$ sodium tartrate ( $\mathrm{pH}$ 4.5). Enzymic activity of manganese peroxidase was determined at $238 \mathrm{~nm}$ by mixing $50 \mu \mathrm{L}$ of culture supernatant with $0.01 \%$ phenol in $0.1 \mathrm{mM} \mathrm{H}_{2} \mathrm{O}_{2}$ and $1 \mathrm{mM} \mathrm{MnSO}_{4}$ in $100 \mathrm{mM}$ sodium tartrate (pH 4.5). Enzymic activity of lignin peroxidase was determined at $310 \mathrm{~nm}$ by the oxidation of $2 \mathrm{mM}$ veratryl alcohol in $100 \mathrm{mM}$ sodium tartrate $\left(\mathrm{pH}\right.$ 4.5) with $0.4 \mathrm{mM} \mathrm{H}_{2} \mathrm{O}_{2}$ and $50 \mu \mathrm{L}$ of culture supernatant. One unit (U) of enzymic activity was defined as the amount of enzyme required to oxidize $1 \mu \mathrm{mol}$ of product per min at $30^{\circ} \mathrm{C}$ and $\mathrm{pH} 4.5$. The enzymic activity obtained from all enzymes were expressed as $\mathrm{U} / \mathrm{mL}$. 


\subsection{Evaluation of $\mathrm{CO}_{2}$ Production}

The amount of $\mathrm{CO}_{2}$ released by potential fungi culturing with LDPE film was determined using a modified sturm test. Sterile air was firstly flowed via $1 \mathrm{M} \mathrm{KOH}$ solution to eliminate atmospheric $\mathrm{CO}_{2}$ prior culturing. Dissolved $\mathrm{CO}_{2}$ in the culture broth was determined by the titration method [31] after 30, 60, and 90 days of incubation at room temperature $\left(27.0 \pm 2.0^{\circ} \mathrm{C}\right)$ with static conditions. The broth of each fungus was filtered, and $25 \mathrm{~mL}$ of filtrate was mixed with $0.05 \mathrm{~mL}$ of $0.1 \mathrm{~N} \mathrm{Na}_{2} \mathrm{~S}_{2} \mathrm{O}_{3}$ and 2 drops of methyl orange in an Erlenmeyer flask. The solution was titrated with $0.02 \mathrm{M} \mathrm{NaOH}$ solution until a yellow color was observed. After that, two drops of phenolphthalein were added into the flask and titration was performed until a pink color was observed. Volumes of the used titrant were recorded. The $\mathrm{CO}_{2}$ amount in the broth was calculated using the following equation: $[\mathrm{A} \times \mathrm{B} \times 50 \times 1000] / \mathrm{V}$, where $\mathrm{A}=$ volume of $\mathrm{NaOH}$ in $\mathrm{mL}$, $\mathrm{B}=$ normality of $\mathrm{NaOH}$, and $\mathrm{V}=$ volume of sample in $\mathrm{mL}$. All chemicals are purchased from Sigma-Aldrich (Singapore).

\subsection{Characterization of LDPE Films by the Potential Fungal Strains}

After the incubation periods, the LDPE films were removed from the fungal culture and rinsed with $70 \%$ ethanol and sterile distilled water [32]. The obtained LDPE films from each fungal culture were air dried at ambient temperature for $24 \mathrm{~h}$ prior to analysis. The weight of each recovered film was recorded using analytical balances. The percentage of weight loss was calculated using the formula [24] $\%$ weight loss $=[($ initial weight - final weight $) /$ initial weight $)] \times 100$. The tensile strength of the LDPE films following degradation tests were also determined using a Universal Testing Machine (UTM; 8800 servo-hydraulic testing machine, Instron, Kawasaki, Japan) in displacement-controlled mode according to the modified method of Amjadi and Fatem [33]. Two dots with a distance of $3 \mathrm{~mm}$ apart in the gage section of the LDPE films were marked. Tension strength was measured between these two marked points. Furthermore, the topography of LDPE films obtained after 30, 60, and 90 days of fungal treatment were analyzed using scanning electron microscopy (SEM; Hitachi SU-70). The dehydrated samples were sputter-coated with gold prior to SEM analysis [25]. The sputtering was performed after placing the pure and dry argon gas in the coating chamber under vacuum. The $10 \mathrm{kV}$ and the $40 \mathrm{~mA}$ current were employed in the system. A thickness of $2 \mathrm{~nm}$ of gold was used during the $45 \mathrm{~s}$ sputtering time. The sample was then examined under the SEM. The chemical structures of LDPE films obtained after 30,60, and 90 days of incubation were characterized using FTIR (Lumos, Bruker, Billerica, MA, USA) with 64 scans at a resolution of $4 \mathrm{~cm}^{-1}$ for each sample [24]. All spectra presented in the results are obtained in the wavenumber range of $600-4000 \mathrm{~cm}^{-1}$. Moreover, the carbonyl index value was calculated as $\mathrm{CI}$. CI is defined as the ratio between the integrated band absorbance of the carbonyl functional group peak from 1850 to $1650 \mathrm{~cm}^{-1}$ to those obtained from the methylene $\left(\mathrm{CH}_{2}\right)$ scissoring peak from 1500 to $1420 \mathrm{~cm}^{-1}$. The $\mathrm{CI}$ values were calculated using the following equation: $\mathrm{CI}=$ area under band $1850-1650 \mathrm{~cm}^{-1} /$ area under band $1500-1420 \mathrm{~cm}^{-1}$ [34].

\subsection{GC-MS Analysis}

After 30,60, and 90 days of incubation, $10 \mathrm{~mL}$ of the broth of each fungus was collected and filtered. VOCs in the obtained supernatant were extracted with $10 \mathrm{~mL}$ of dichloromethane (Sigma-Aldrich, Singapore) using a separatory funnel following a modified method from Park and Kim [35]. VOCs emitted from the LDPE film were analyzed using the GC-MS system (Agilent Technologies, Santa Clara, CA, USA). The capillary column was an HP- $5 \mathrm{~ms}$ ( $30 \mathrm{~m} \times 0.25 \mathrm{~mm}$ i.d., $0.25 \mu \mathrm{m}$ film thickness) (Agilent Technologies, Santa Clara, CA, USA). The oven temperature was initially held at $60^{\circ} \mathrm{C}$ and then increased at a rate of $5{ }^{\circ} \mathrm{C} / \mathrm{min}$ to a final temperature of $220^{\circ} \mathrm{C}$. The injector temperature was set to $250{ }^{\circ} \mathrm{C}$. Helium was used as a carrier gas with a flow rate of $1 \mathrm{~mL} / \mathrm{min}$. Electron impact mass spectra were collected at $70 \mathrm{eV}$ over the range of $30-300 \mathrm{~m} / \mathrm{z}$. The ion source and analyzer temperatures were set to 250 and $230{ }^{\circ} \mathrm{C}$, respectively. Identification of VOCs 
was performed by comparing their mass spectra with those found in the NIST14 Mass Spectral Library.

\subsection{Statistical Analysis}

All experiments were performed in triplicate five times. Data from each experiment were presented as the mean \pm standard deviation. Data were subjected to Analysis of variance (ANOVA) followed by post hoc multiple pairwise comparisons using Duncan's multiple range tests with a reference treatment $(\alpha=0.05)$. The statistical analyses were conducted using the SPSS 20.0 software (IBM Corp). The data for each bar in all figures are mean \pm standard deviation. Different letters above the bars indicate significant differences $(p<0.05)$ among the samples (ANOVA, followed by Duncan's multiple range test).

\section{Results}

\subsection{Screening of Potential Fungi for LDPE Film Degradation}

All fungal strains as described above were tested for their ability to degrade LDPE films as a carbon source on a liquid medium. The growth ability of fungi culturing with LDPE film after 30 days of incubation was evaluated as mycelium dry weight of the fungi (Figure 1). The mycelium dry weight of fungi varied from 0 to $0.25 \mathrm{~g}$. Five efficient fungi, including D. italiana, T. jaczewskii, C. fructicola, S. citrulli and A. niger, were able to grow significantly in media, showing a mycelium dry weight of $0.25,0.18,0.19,0.19$, and $0.18 \mathrm{~g}$, respectively, compared to those obtained from other fungi. Therefore, these fungi were further analyzed for their degradation ability.

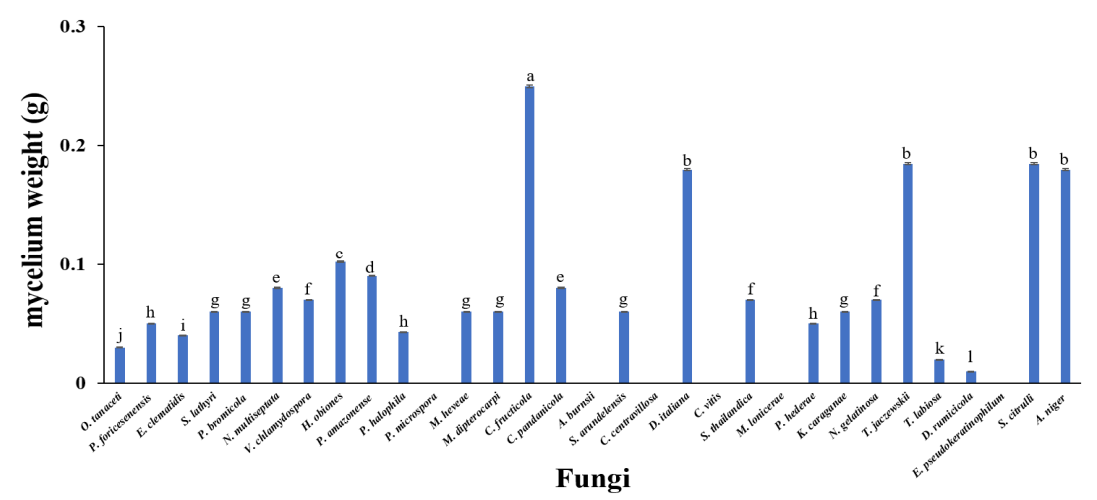

Figure 1. Mycelium dry weight of fungi cultured with LDPE film after 30 days of incubation. Different letters above the bars indicate significant differences $(p<0.05)$.

\subsection{Enzyme Activity of Potential Fungi}

The enzymatic activity of laccase, manganese peroxidase, and lignin peroxidase secreted by potential fungi are depicted in Figure 2. All fungi were able to secrete all enzymes. The enzymic activity was enhanced when the incubation period was increased. However, enzyme laccase was highly secreted by all fungi compared to other enzymes in the same conditions. The $C$. fructicola fungus secreted the highest level of laccase after 90 days of incubation, with $70.67 \mathrm{U} / \mathrm{mL}$, while other fungi secreted laccase ranging from 41.78 to $51.56 \mathrm{U} / \mathrm{mL}$. Enzyme manganese peroxidase was detected with a similar content in all fungi, ranging from 6.33 to $10.37,15.75$ to 22.77 , and 31.11 to $38.45 \mathrm{U} / \mathrm{mL}$ after 30,60 , and 90 days of incubation, respectively. In addition, lignin peroxidase was also detected in all fungi, ranging from 2.33 to $6.45,5.68$ to 17.66 , and 10.26 to $31.45 \mathrm{U} / \mathrm{mL}$ after 30,60 , and 90 days of incubation, respectively. 


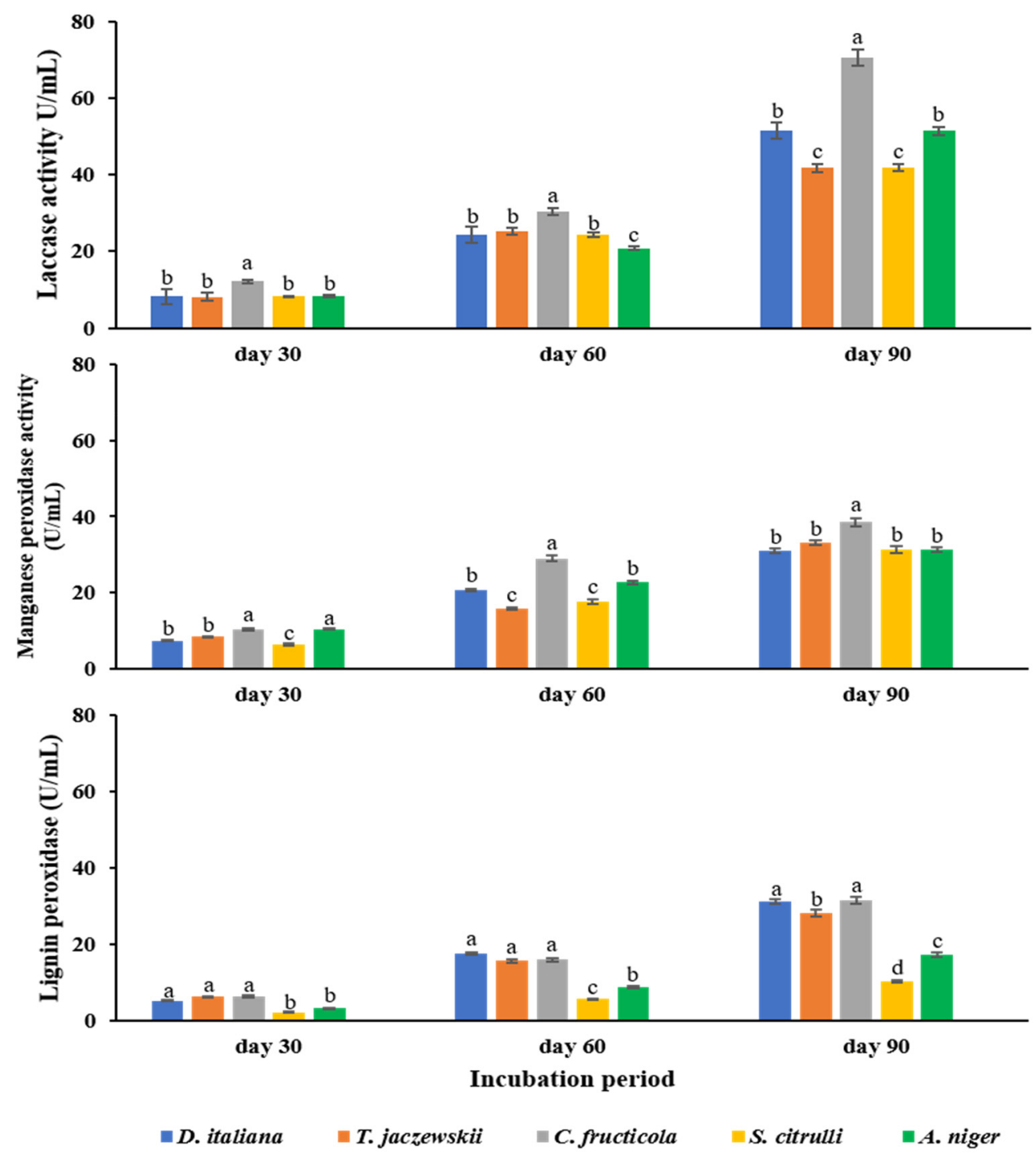

Figure 2. Enzymic activity in D. italiana, T. jaczewskii, C. fructicola, S. citrulli, and A. niger culture supernatant after 30,60, and 90 days of incubation. Different letters above the bars indicate significant differences $(p<0.05)$.

\section{3. $\mathrm{CO}_{2}$ Production from Potential Fungi}

The amount of $\mathrm{CO}_{2}$ dissolved in the culture broth of D. italiana, T. jaczewskii, C. fructicola, S. citrulli, and A. niger after 30,60, and 90 days of incubation is shown in Figure 3. The fungus $C$. fructicola demonstrated the highest amount of $\mathrm{CO}_{2}$ compared to other fungi, ranging from 0.45 to 0.99 , and $1.45 \mathrm{~g} / \mathrm{mL}$ after $30,60,90$ days of incubation, respectively. Similar $\mathrm{CO}_{2}$ amounts were detected in broths of D. italiana, T. jaczewskii, S. citrulli, and A. niger ranging from 0.36 to $1.22,0.45$ to $1.45,0.33$ to 1.26 , and 0.37 to $1.27 \mathrm{~g} / \mathrm{L}$, respectively, after 90 days of incubation. 


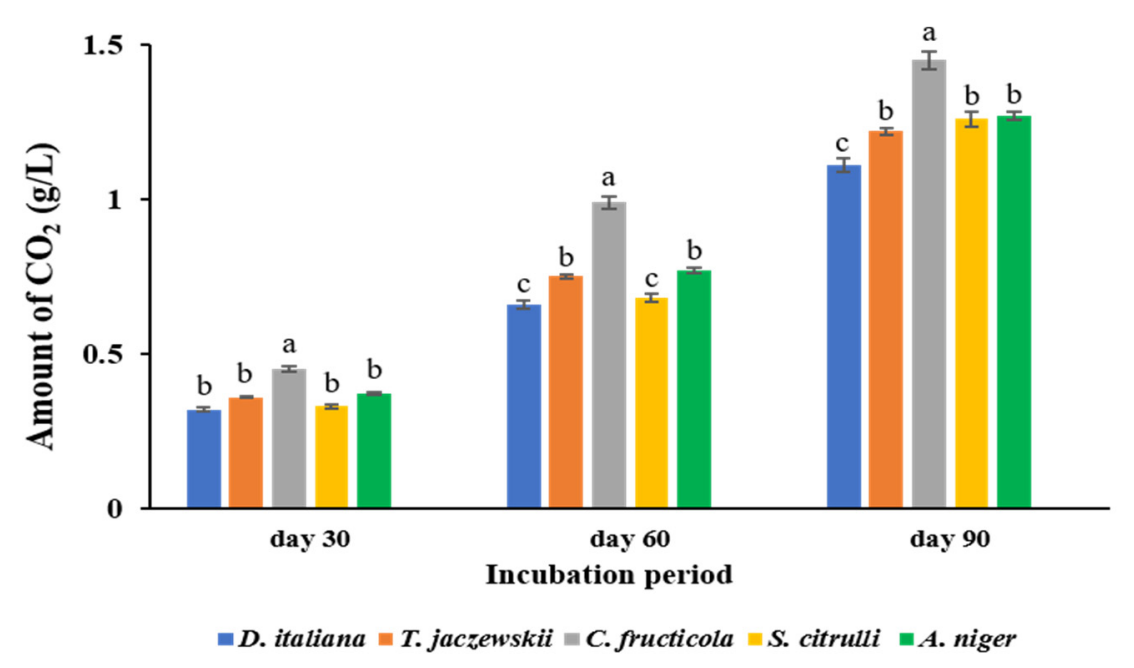

Figure 3. Amount of $\mathrm{CO}_{2}$ dissolved in D. italiana, T. jaczewskii, C. fructicola, S. citrulli, and A. niger broth after 30,60, and 90 days of incubation. Different letters above the bars indicate significant differences $(p<0.05)$.

\subsection{Determination of Weight Loss of LDPE Films}

Biodegradation of LDPE films by culturing with culture medium of D. italiana, T. jaczewskii, C. fructicola, S. citrulli, and A. niger was evaluated after 30, 60, and 90 days of incubation (Figure 4). It was found that the weight loss of LDPE films during the incubation with the five efficient fungal strains was resulted from the utilization of the polyethylene as the sole carbon source. The results indicate that these fungal strains were capable of degrading LDPE films, and that the fungus $C$. fructicola showed the highest LDPE film degradation ability, with $17.07 \%, 28.05 \%$, and $48.78 \%$ after 30,60 , and 90 days of incubation, respectively. The weight loss percentages of LDPE films cultured with broths of the D. italiana fungus were $12.20 \%, 18.29 \%$, and $43.90 \%$ after 30,60 , and 90 days of incubation, respectively. Similarly, the percentage of weight loss of LDPE films was also increased after culturing with culture broths of $T$. jaczewskii, with $7.32 \%, 20.73 \%$, and $46.34 \%$ after 30,60 , and 90 days of incubation, respectively. LDPE films from S. citrulli culture revealed weight loss percentages of $7.32 \%, 24.39 \%$, and $45.12 \%$ after 30,60 , and 90 days of incubation, respectively. The LDPE films from the $A$. niger culture showed weight loss percentages of $8.85 \%, 16.83 \%$, and $28.78 \%$ after 30,60 , and 90 days of incubation, respectively.

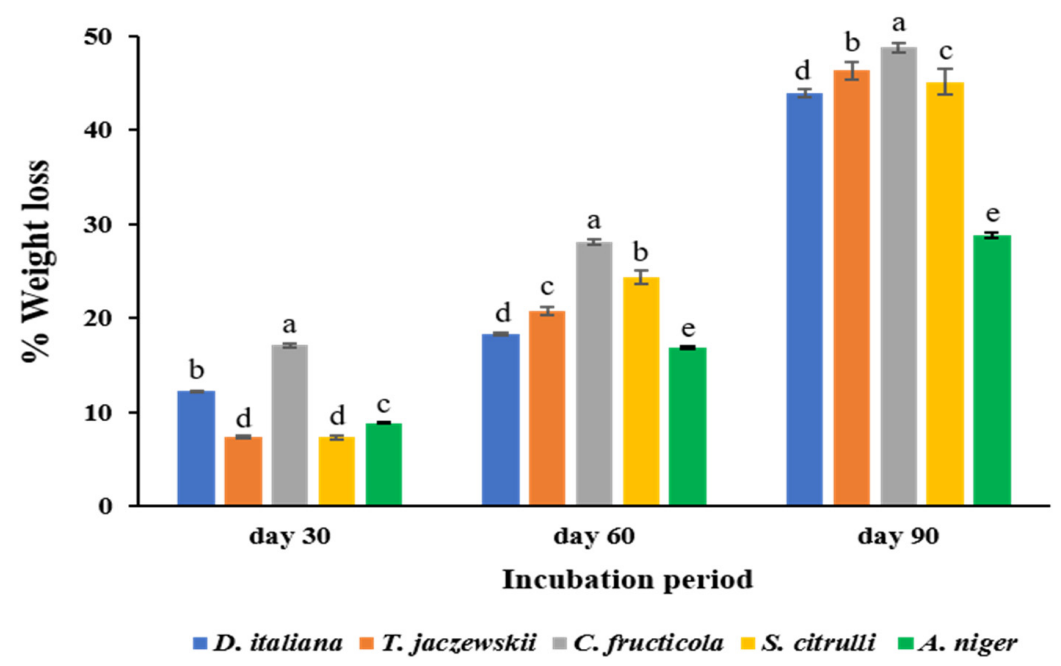

Figure 4. Weight loss percentage of LDPE films cultured with D. italiana, T. jaczewskii, C. fructicola, S. citrulli, and A. niger after 30,60, and 90 days of incubation. Different letters above the bars indicate significant differences $(p<0.05)$. 


\subsection{Determination of Tensile Strength of LDPE Films}

The tensile strength values of LDPE films cultured with D. italiana, T. jaczewskii, C. fructicola, S. citrulli, and A. niger after 30, 60, and 90 days of incubation are shown in Figure 5. C. fructicola was able to reduce the tensile strength of LDPE films at the highest rate after incubation of 30,60 , and 90 days of incubation to $8.26,4.35$, and $0.43 \mathrm{MPa}$, respectively. The strength of the LDPE films was reduced significantly to $8.26 \mathrm{MPa}, 4.35$, and $1.56 \mathrm{MPa}$ after culturing with D. italiana after 30, 60, and 90 days of incubation. The fungi T. jaczewskii also showed a significant decrease in tensile strength after 30, 60, 90 days of incubation to $8.16,5.28,1.78 \mathrm{MPa}$, respectively. The fungus $S$. citrulli revealed tensile strengths of LDPE films of $8.26,4.35$, and $1.86 \mathrm{MPa}$, respectively, whereas tensile strengths of LDPE films of 6.45, 5.77, and 3.34MPa were determined in LDPE films culturing with A. niger after 30, 60, and 90 days of incubation. The percentage of tensile strength of LDPE films culturing with D. italiana, T. jaczewski, C. fructicola, S. citrulli, and A. niger was reduced to $6.40 \%, 5.61 \%, 23.21 \%, 5.37 \%$, and $2.99 \%$, respectively, after 90 days of incubation. This indicates that LDPE films cultured with these fungal cultures were fragile.

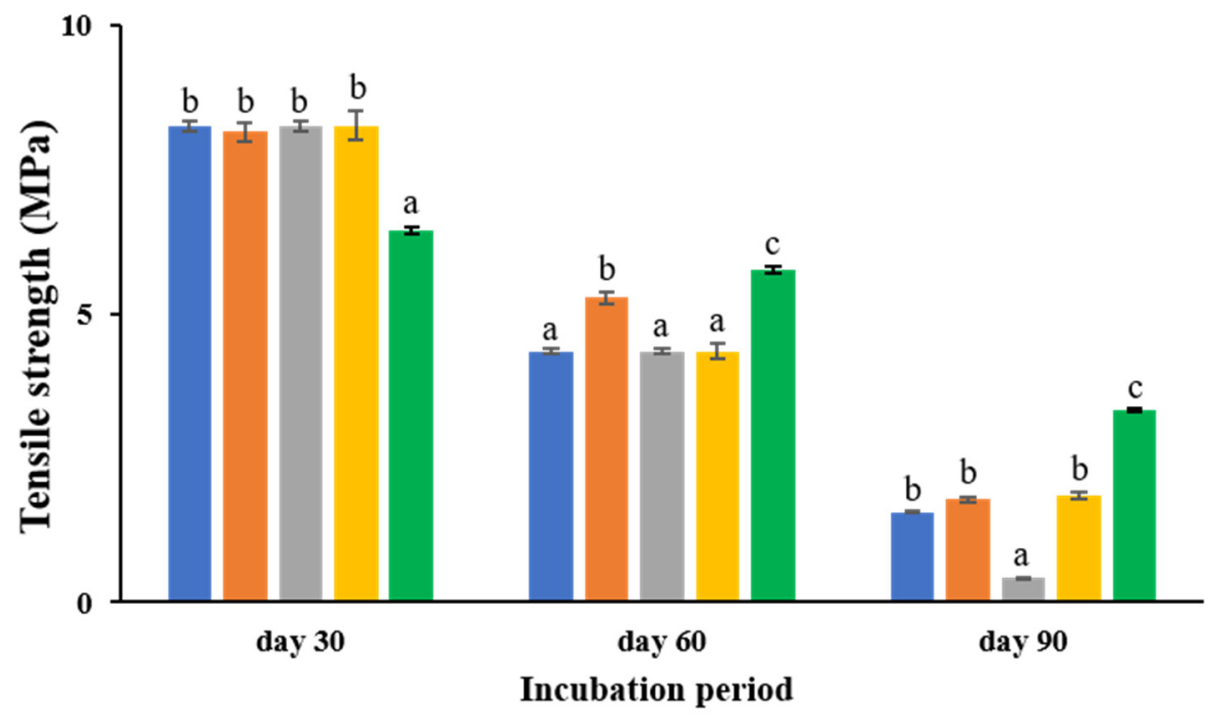

$\square$ D. italiana $=$ T. jaczewskii $\backsim$ C. fructicola $\amalg S$. citrulli $\square$ A. niger

Figure 5. Tensile strength of LDPE films cultured with D. italiana, T. jaczewskii, C. fructicola, S. citrulli, and A. niger after 30,60, and 90 days of incubation. Different letters above the bars indicate significant differences $(p<0.05)$.

\subsection{FTIR and the CI Analysis of the LDPE Films}

The LDPE films cultured with culture broths of D. italiana, T. jaczewskii, C. fructicola, S. citrulli, and A. niger after 30,60, and 90 days were analyzed by FTIR, and the spectra are shown in Figure 6. The absorption strong band for aliphatic $\mathrm{CH}$ was observed at 2954 and $2856 \mathrm{~cm}^{-1}$ in the spectra of all samples. Characteristic bands of low intensity at 1740,1624 , and $1546 \mathrm{~cm}^{-1}$ depicted in LDPE films were obtained from the spectra of these fungi. A quite low intensity of the broad band at $3370 \mathrm{~cm}^{-1}$ was also detected in LDPE films obtained after culturing with these fungal culture broths. Medium bands at 1470 and $1420 \mathrm{~cm}^{-1}$ were assigned to $\mathrm{CH}_{3}$ deformation, and 1228 and $1055 \mathrm{~cm}^{-1}$ to C-O-C stretching were also detected in the spectra of LDPE films obtained from all fungi. Similarly, all LDPE films showed absorbance in the range of $700-900 \mathrm{~cm}^{-1}$ corresponding to $-\mathrm{C}=\mathrm{C}$ - stretching and the presence of alkene groups. 


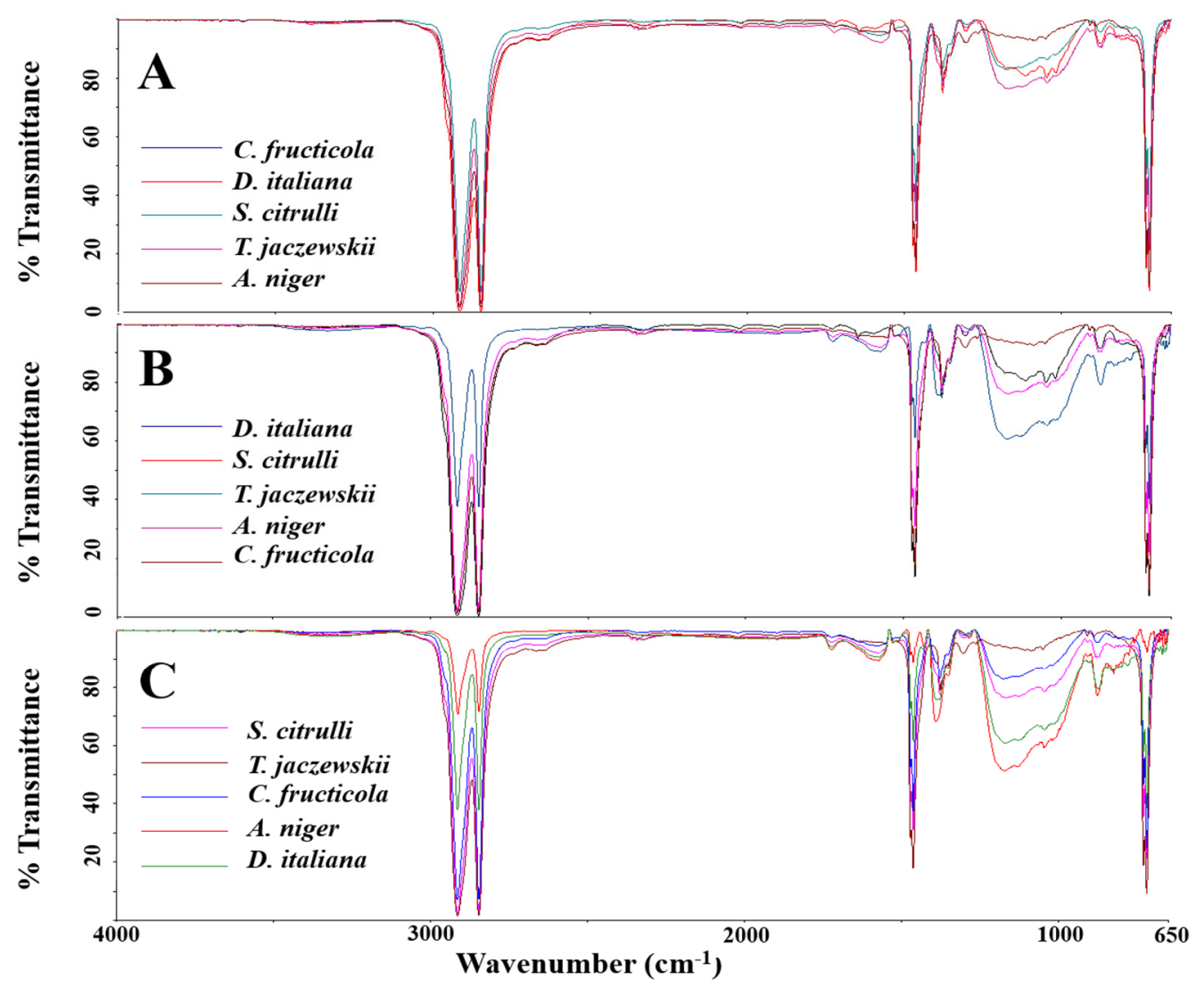

Figure 6. Spectra from FTIR analysis of LDPE films cultured with D. italiana, T. jaczewskii, C. fructicola, S. citrulli, and A. niger after 30 (A), 60 (B), and 90 (C) days of incubation.

The CI of the LDPE films by culturing with culture broths of D. italiana, T. jaczewskii, C. fructicola, S. citrulli, and A. niger after 30, 60, and 90 days of incubation were also calculated and depicted in Figure 7. The decrease in the CI was determined to confirm the oxidation of LDPE films by the tested fungi. The CIs for the LDPE films when culturing with D. italiana, T. jaczewskii, C. fructicola, S. citrulli, and A. niger, after 30, 60, and 90 days of incubation were $16.45-8.18,18.16-1.34,15.45-0.74,16.33-0.86$, and $16.37-1.47$, respectively.

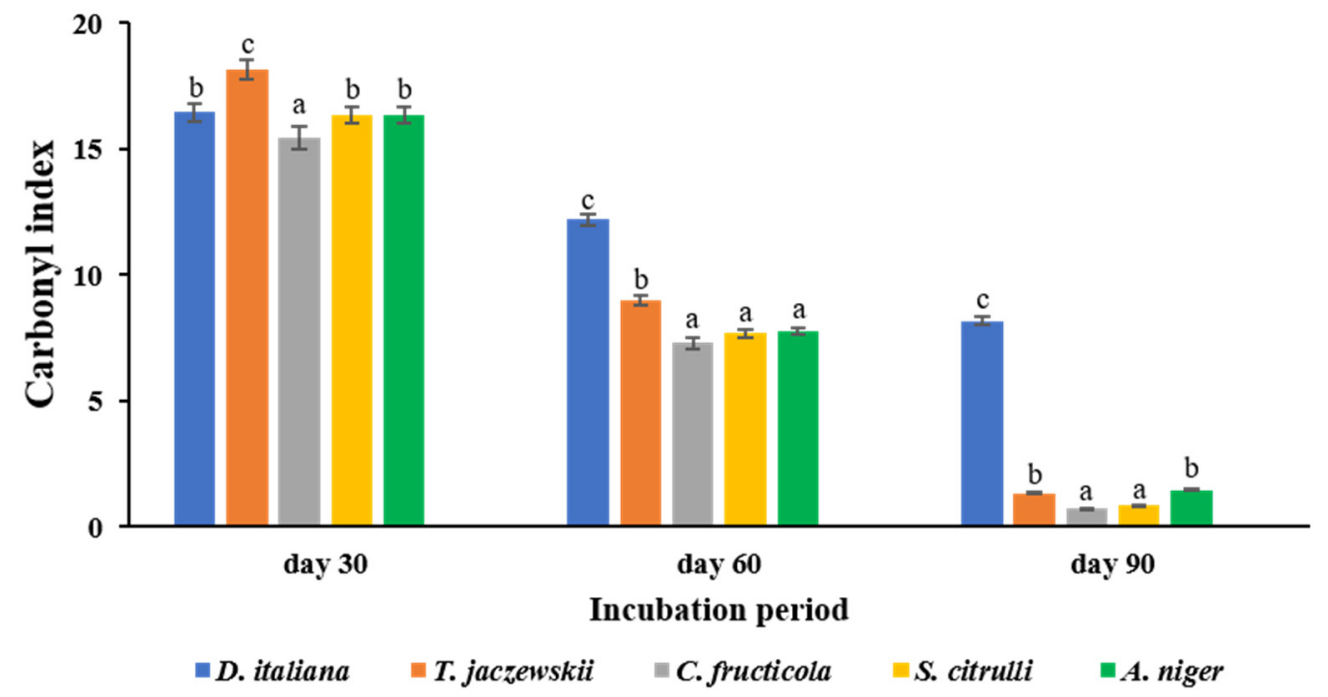

Figure 7. The carbonyl indexes of the of LDPE films cultured with D. italiana, T. jaczewskii, C. fructicola, S. citrulli, and A. niger after 30, 60, and 90 days of incubation. Different letters above the bars indicate significant differences $(p<0.05)$. 


\subsection{Characterization of the LDPE Films by SEM Analysis}

To confirm the biodegradation of LDPE films by the tested fungi, the LDPE films were analyzed by SEM. The surface morphology of the LDPE films cultured with culture broths of D. italiana, T. jaczewskii, C. fructicola, S. citrulli, and A. niger after 30, 60, and 90 days of incubation are demonstrated in Figure 8. In the case of D. italiana, T. jaczewskii, C. fructicola, S. citrulli, and A. niger, various structural changes such as grooves, cracks, damaged layer, fragileness, pits and roughening of the surface were observed after 30, 60 , and 90 days of incubation. No apparent structural changes were found on day 0 . In the case of LDPE films treated by the fungus $C$. fructicola, attachment of the spores was observed after 60 and 90 days of incubation.
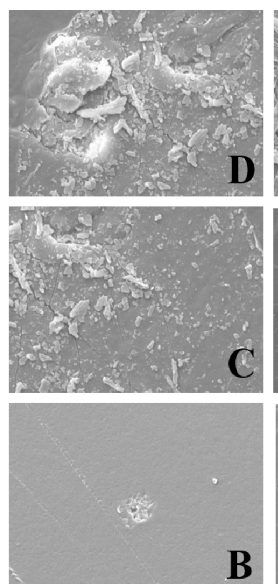

B

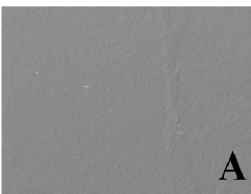

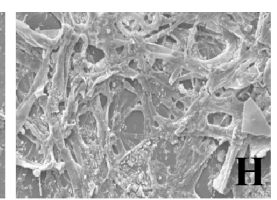
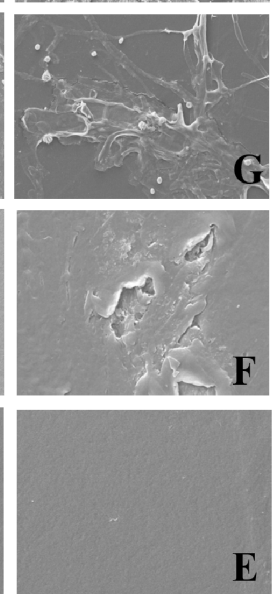
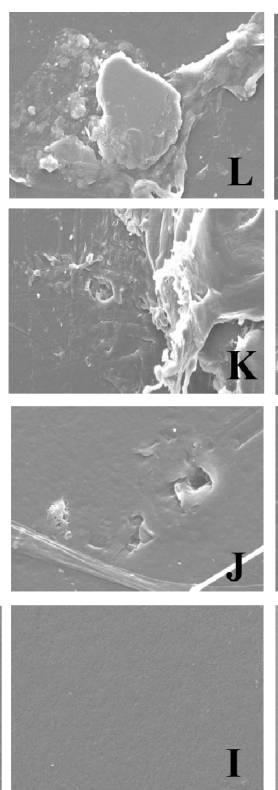
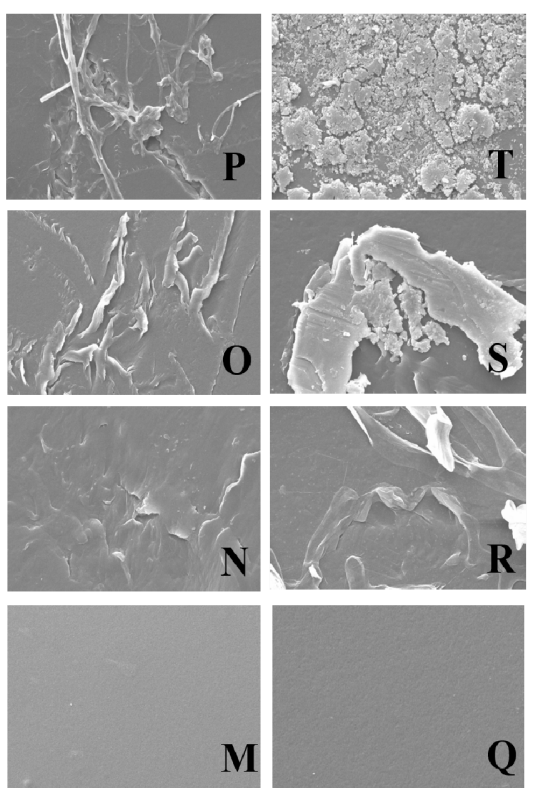

$\mathbf{M}$

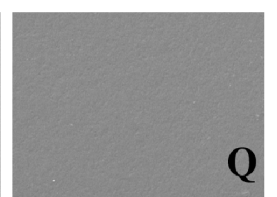

Figure 8. Scan electron micrographs of LDPE films $(1000 \times)$ cultured with D. italiana (A-D), C. fructicola (E-H), T. jaczewskii (I-L), S. citrulli (M-P), and A. niger (Q-T) after 0, 30, 60, and 90 days of incubation, respectively.

\subsection{GC-MS Analysis}

VOCs emitted from LDPE films culturing with D. italiana, T. jaczezwskii, C. fructicola, S. citrulli, and A. niger after 30, 60, and 90 days of incubation was determined using GCMS analysis. GC-MS chromatograms of VOCs emitted from LDPE films after 30, 60, and 90 days of incubation are shown in Figures 9-11, respectively. The number of VOCs and peak height increased with the increasing incubation period. A total of 27 VOCs was detected among these samples obtained from 90 days of incubation. The quantitative result is shown in Table 1. The highest number of VOCs (22 compounds, representing $98.85 \%$ of the total amount) was detected from C. fructicola when compared with those emitted from T. jaczewskii (21 compounds, representing 99.85\% of the total amount), A. niger (15 compounds, representing $98.77 \%$ of the total amount), D. italiana (15 compounds, representing $96.87 \%$ of the total amount), and S. citrulli (8 compounds, representing $98.77 \%$ of the total amount). 


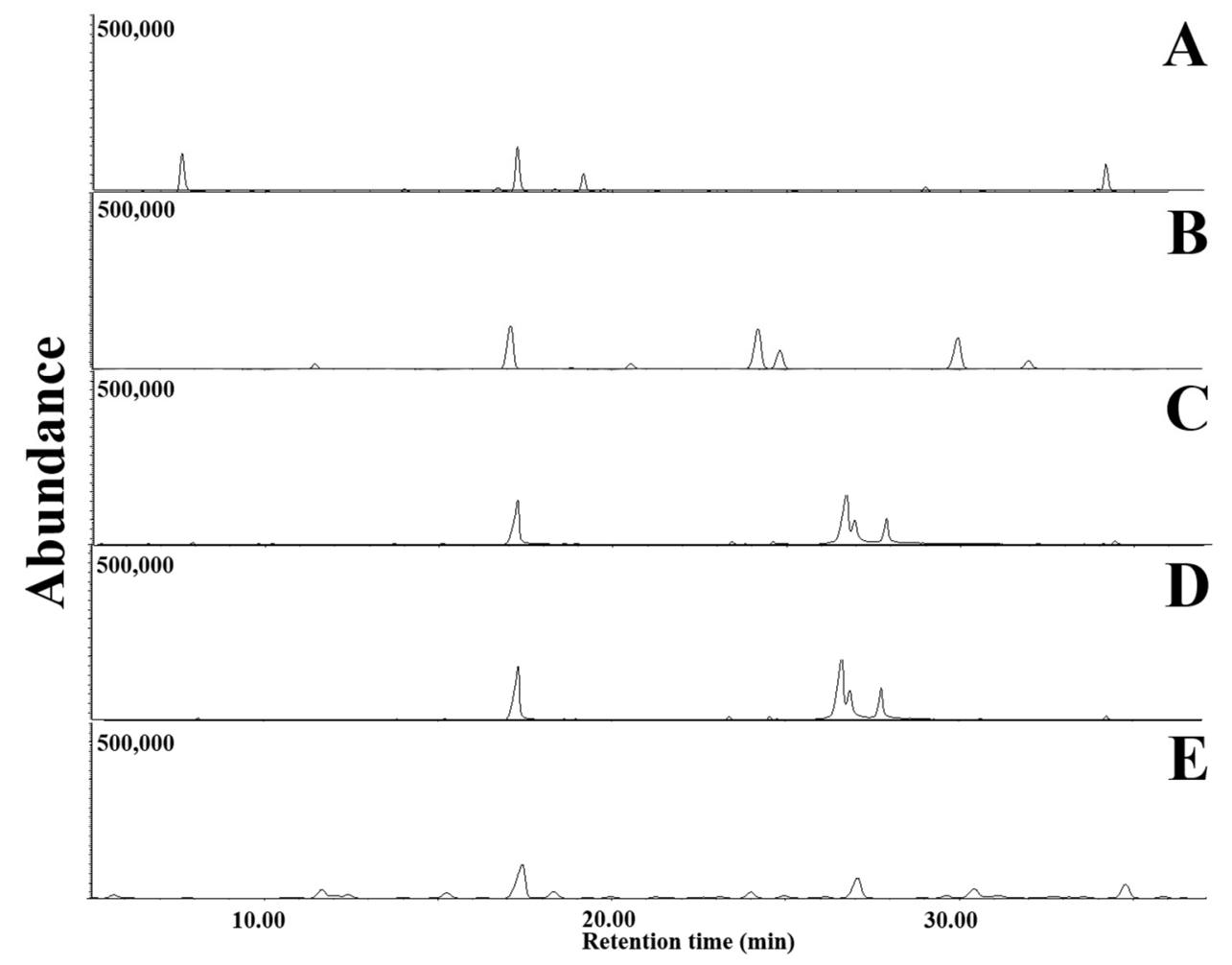

Figure 9. GC-MS chromatograms of dichloromethane extracts of LDPE films cultured with $T$. jaczewskii (A), S. citrulli (B), A. niger (C), D. italiana (D), and C. fructicola (E) after 30 days of incubation, respectively.

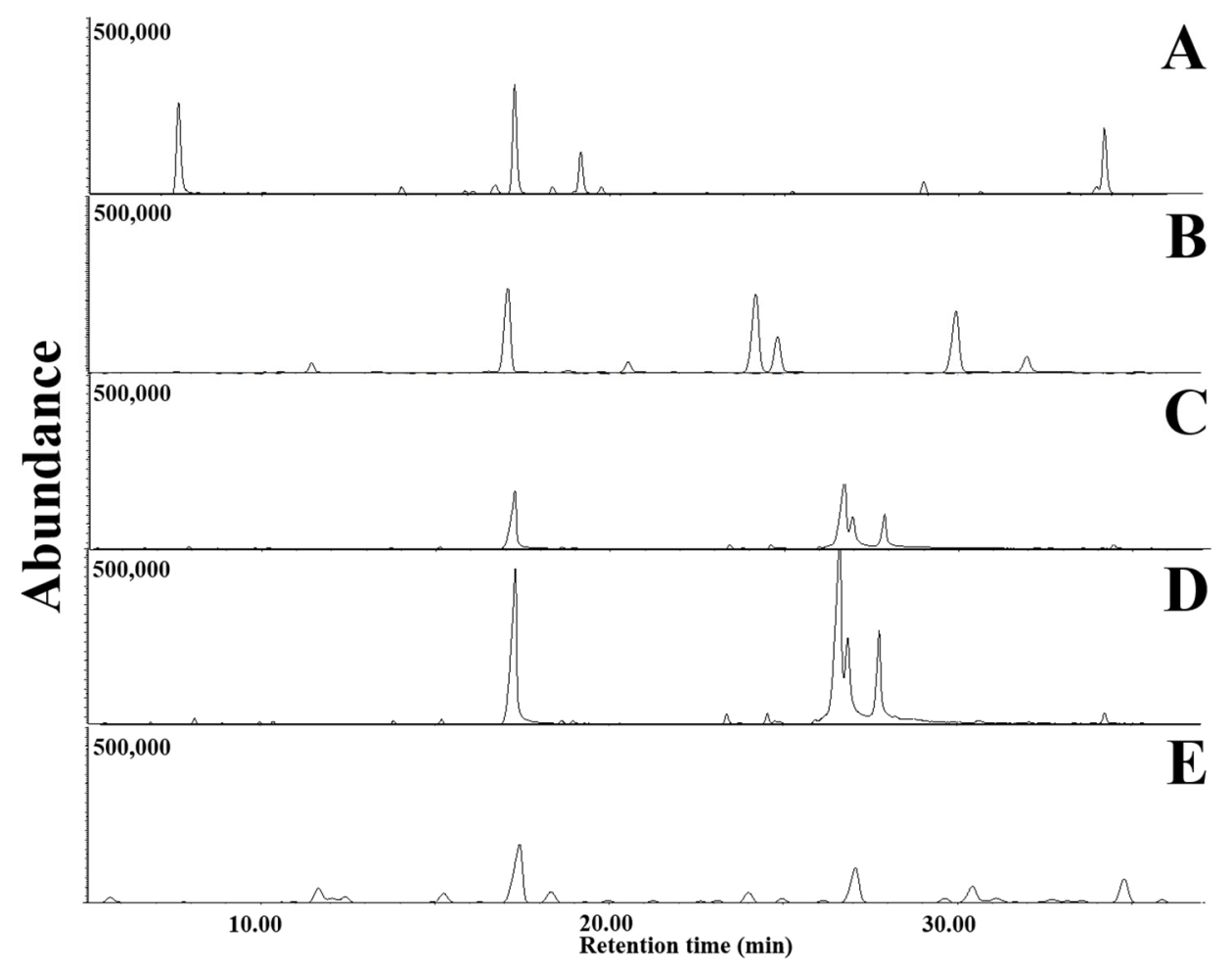

Figure 10. GC-MS chromatograms of dichloromethane extracts of LDPE films cultured with T. jaczewskii (A), S. citrulli (B), A. niger (C), D. italiana (D), and C. fructicola (E) after 60 days of incubation, respectively. 


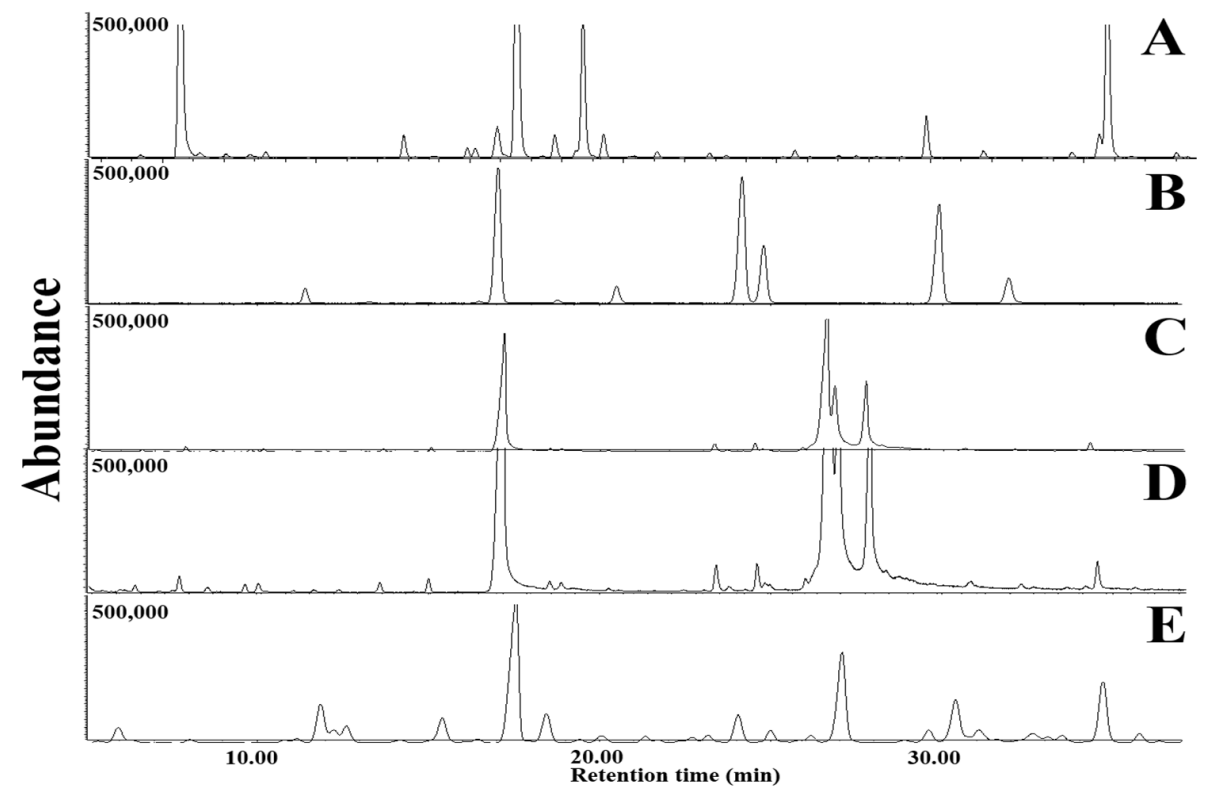

Figure 11. GC-MS chromatograms of dichloromethane extracts of LDPE films cultured with $T$. jaczewskii (A), S. citrulli (B), A. niger (C), D. italiana (D), and C. fructicola (E) after 90 days of incubation, respectively.

Table 1. VOCs emitted from LDPE films cultured with T. jaczewskii, S. citrulli, A. niger, D. italiana, and C. fructicola after 90 days of incubation.

\begin{tabular}{|c|c|c|c|c|c|c|}
\hline No. & Compound & T. jaczewskii & S. citrulli & D. italiana & C. fructicola & A. niger \\
\hline 1 & hexadienal & 1.81 & & 0.78 & & 0.82 \\
\hline 2 & methyl-1,4-cyclohexadiene & 10.21 & & 0.25 & 6.21 & 0.23 \\
\hline 3 & octene & 1.67 & & 1.23 & & 0.58 \\
\hline 4 & 3,3,5-trimethyl-cyclohexene & 2.45 & & 0.21 & 0.11 & 0.23 \\
\hline 5 & 3,5,5-trimethyl-cyclohexene & 2.57 & & 0.31 & 0.11 & 0.31 \\
\hline 6 & 2E-methyl-3-octen-5-yne & & & 1.12 & 0.34 & 1.09 \\
\hline 7 & 1,2,3-trimethyl benzene & & 3.23 & & 4.34 & \\
\hline 8 & decene & & & 0.48 & 0.12 & 0.59 \\
\hline 9 & decane & & & 0.86 & 1.19 & 0.98 \\
\hline 10 & 1,2,4-trimethyl benzene & 3.87 & & & & \\
\hline 11 & 2-methoxyethyl-benzene & 0.21 & & 0.79 & 0.98 & 0.84 \\
\hline 12 & pentyl-benzene & 1.89 & & & 3.45 & \\
\hline 13 & 1,4- dimethoxybenzene & 0.86 & 0.11 & & 0.32 & \\
\hline 14 & 1,3-dimethoxy-benzene & 2.67 & 18.48 & 21.32 & 32.01 & 23.54 \\
\hline 15 & Undecanal & 22.21 & & & 5.37 & \\
\hline 16 & undec-9Z-en-1-al & 1.21 & & & 0.23 & \\
\hline 17 & phenyl pentan-3-one & 12.23 & 3.43 & & 0.63 & \\
\hline 18 & $\begin{array}{c}\text { 1,3-dimethoxy-5-(1-methylethyl)- } \\
\text { benzene }\end{array}$ & 4.11 & 17.22 & 1.34 & 4.34 & 1.48 \\
\hline 19 & trimethyl benzaldehyde & 1.91 & & & & \\
\hline 20 & 2E-undecenal & 0.24 & 14.58 & 1.42 & 3.19 & 1.31 \\
\hline 21 & 1,1-dimethoxy-decane & 1.02 & & 50.13 & 17.56 & 51.11 \\
\hline 22 & 2E,6Z-diethylacetal-nonadienal & & & 15.34 & & 14.38 \\
\hline 23 & phenyl-4-methyl-pentan-3-one & 15.35 & 24.76 & & 0.18 & \\
\hline 24 & hexyl hexanoate & & & & 7.01 & \\
\hline 25 & 3Z-hexenyl-3Z-hexenoate & 1.13 & 15.34 & & 0.88 & \\
\hline 26 & isobutyl phenylacetate & 2.21 & & 1.29 & & 1.28 \\
\hline \multirow[t]{3}{*}{27} & 2-dodecanone & 10.02 & & & 10.28 & \\
\hline & Total of $\%$ area & 99.85 & 97.15 & 96.87 & 98.85 & 98.77 \\
\hline & No. of VOCs & 21 & 8 & 15 & 22 & 15 \\
\hline
\end{tabular}


Undecanal, phenyl-4-methyl-pentan-3-one, and phenyl pentan-3-one were found to be the major compounds in LDPE film culturing with T. jaczewskii. Meanwhile, phenyl4-methyl-pentan-3-one, 1,3-dimethoxy-benzene, and 1,3-dimethoxy-5-(1-methylethyl)benzene were detected in high amounts in LDPE film culturing with $S$. citrulli. Similar major compounds including 1,1-dimethoxy-decane, 1,3-dimethoxy-benzene, and 2E,6Zdiethylacetal-nonadienal were detected in LDPE film culturing with $A$. niger and $D$. italiana, while 1,3-dimethoxy-benzene, 1,1-dimethoxy-decane, and 2-dodecanone were considered as major compounds in LDPE film culturing with $C$. fructicola.

\section{Discussion}

This study consists of both saprotrophic and plant pathogenic fungi such as $O$. tanacetiand, E. clematidis, M. heveae, S. citrulli, T. jaczewskii, and $H$. obiones $[26,27,36]$. Some fungi are known as plant pathogens, such as C. fructicola [37], and D. italiana [38]. The degradation ability of fungi cultured with the culture broths was depicted via weight loss percentage, tensile strength, formation of cracks/scars/holes on the surface of the LDPE films, and changes in the CI $[5,39]$. This is the first study that demonstrates the degradation of LDPE films by fungi obtained from Thailand. From the preliminary screening, four fungal species showed degradation potential: D. italiana, T. jaczewskii, C. fructicola, and S. citrulli, compared to $A$. niger, which has been reported to have degradation ability $[40,41]$. The different degradation potential of all tested fungi may be mainly influenced by various other factors, such as incubation period, temperature, humidity, carbon source, and $\mathrm{pH}[39,42]$.

The efficiency of degradation by active fungi was further confirmed using liquid medium with which the carbon sources for the growth of fungi were limited. The growth rate of each fungus on the surface of LDPE films in the liquid medium varied at room temperature. This result may be because the degradation temperature plays an important role in biodegradation [40-42]. Although several reports presented the potential of $A$. niger for LDPE degradation [39-43], the active fungi in this study showed significantly higher potential during the same incubation period.

These potential fungi were able to secrete different enzymes in terms of qualitative and quantitative analysis. This result may be dependent on genotype in nature [31]. Recently, biodegradation of LDPE polymer was enhanced by extracellular enzymes produced by the potential microorganism [31,35]. Therefore, enzyme levels in broths of these potential fungi indicated the degenerative activity. The level of the enzyme laccase was higher in all cultures growing with LDPE film, probably due to the greater demand for polymer breakdown reactions. The fungus $C$. fructicola showed a remarkably higher level of the enzyme laccase as compared to other fungi. This may be due to great contribution with biomass accumulation. Several polyethylene degrading enzymes were reported such as phylloplane fungal enzymes from Paraphoma-like phylloplane fungus [44], laccase, and manganese peroxidase from Penicillium simplicissimum [45]. Some fungi have been evaluated to secrete the enzyme depolymerase, which is responsible for hydrolyzing and breaking polymers into oligomers and monomers such as Penicillium pinophyllum [44], Paecilomyces lilacinus [46], and Fusarium moniliforme [47]. The products of the reaction were then further transformed into water and carbon dioxide. However, the degradation mechanism of fungi is not exactly known. Gu et al. [48] reported that at least two categories of enzymes, including extracellular and intracellular depolymerases, were mainly related in the depolymerization process of polymer degradation. During the degradation process, extracellular enzymes from fungi break down complex polymers into oligomers, dimers, and monomers. These products are sufficiently small and can be further utilized as carbon sources $[44,45]$. Their mechanism involved in biodegradation pathways will be further studied for searching for new or alternative technologies for degrading these environmentally hazardous LDPE films.

In general, $\mathrm{CO}_{2}$ released by fungi culturing with LDPE film was also evaluated as a reliable indicator of biodegradation ability [49]. During the incubation period, these potential fungi enzymatically degraded polymer chains of LDPE films and released $\mathrm{CO}_{2}$. These 
potential fungi showed a great amount of $\mathrm{CO}_{2}$ after the incubation period, demonstrating degradation ability. Pramila and Ramesh [50] reported that higher amount of $\mathrm{CO}_{2}$ was released by Aspergillus species culturing with LDPE films. Shah et al. [51] revealed a great amount of $\mathrm{CO}_{2}$ in a Fusarium culture from sewage waste culturing with polyethylene bag pieces. Esmaeili et al. [42] reported that the amount of $\mathrm{CO}_{2}$ was significantly higher in treatments supplemented with the potential fungi.

High weight loss of LDPE films obtained from culturing with the culture broths may be due to the breakdown of its carbon backbone via enzymatic degradation processes by the fungi, thereby producing monomers and oligomers as a carbon source [52]. The tensile strength, one of the main parameters of LDPE films, was also determined. It was found that a strong correlation between weight loss percentage and tensile strength was depicted. The highest weight loss and lowest tensile strength were shown in the LDPE films cultured with culture broths of C. fructicola, followed by those of T. jaczewskii, S. citrulli, and D. italiana, respectively. Our report is in good agreement with the study by Vijaya and Reddy [53]. They reported the correlation coefficient between weight loss and tensile strength. A strong correlation coefficient was achieved when weight loss was affected by microbial attacks, and that tensile strength also affected at the same time.

In the present study, the FTIR data confirm changes in bond scission, chemical transformation, formation, and disappearance of new functional groups in the LDPE films. These changes indicate that the LDPE films may be degraded by the fungal enzymes, resulting in the breakdown and formation of some chemical bonds [4,5,54]. For example, 3-poly hydroxybutyrate depolymerase (PHB), it was secreted by Penicillium pinophyllum [24] and responsible for hydrolyzing of ester bonds in polyethylene and breaking it into oligomers and mono (3 hydroxybutyrate). The changes in the detected spectrum were correlated with band intensity and the possible displacement of these bands or their appearance [55]. The degradation rate was increased with incubation time. The peaks were broader as various monomeric forms and oxidation products of the LDPE films were generated [56]. No significant changes were observed among LDPE films obtained from culturing with these fungal cultures. However, some changes were present, such as the bands at $1740 \mathrm{~cm}^{-1}$ $\left(\mathrm{C}=\mathrm{O}\right.$ groups stretching in the amorphous phase) and $1720 \mathrm{~cm}^{-1}(\mathrm{C}=\mathrm{O}$ groups stretching in the crystalline phase), and the new bands appearing at 1624 and $1546 \mathrm{~cm}^{-1}$ correspond to $\mathrm{C}=\mathrm{O}$ acid and $\mathrm{C}=\mathrm{C}$ vibration bands, respectively. The appearance of the band at $3370 \mathrm{~cm}^{-1}$ (broad band) corresponds to the $\mathrm{O}-\mathrm{H}$ vibration of acids. These changes could be attributed to the presence of organic carboxylic acid produced from hydrolysis reactions by fungal enzymes [57]. The significant bands at 1470, 1420, 1228, and $1055 \mathrm{~cm}^{-1}$ obtained from $\mathrm{CH}_{3}$ deformation and $\mathrm{C}-\mathrm{O}-\mathrm{C}$ stretching were sensitive to the polymer crystallization which decreases the band intensity and film crystallinity in the $\mathrm{C}-\mathrm{O}-\mathrm{C}$ ester group [58]. Bands at $700-900 \mathrm{~cm}^{-1}$ corresponding to $-\mathrm{C}=\mathrm{C}$ - stretching and the presence of alkene groups found in the LDPE may also be generated from hydrolysis reactions by fungal enzymes [42]. FTIR analysis shows that the LDPE films were degraded significantly by the fungus $C$. fructicola possibly via the enzymatic hydrolysis reaction promoting the microbial action. The CI value, which determines the degradation rate, decreased when the incubation time was increased and was observed to be the lowest for the fungus. The decreased CI confirmed the concept that oxidized polymers are utilized by the fungi [59]. In addition, Pathak [60] reported that the degradation rate of polymers depends on the time required for the growth phase of fungal culture and the addition of functional groups from VOCs emitted from LDPE films.

The degradation of the LDPE films was further confirmed using SEM analysis. The SEM analysis revealed the degradation level on the surface of the LDPE films in the form of cracks, scions, and holes. The SEM images confirmed that these five fungal strains were able to break down the complex structure of polyethylenes of LDPE into their monomeric forms. The cracks also confirmed the fragility of LDPE films cultured with these fungal cultures. The degradation was enhanced by the formation of biofilms by fungi as reported by Das and Kumar [61]. The fungal strains were colonized on the LDPE film by utilizing 
their film as the sole carbon source, and the fungal hyphae have successfully been coalesced with LDPE film by growing over the film surface. Our SEM analysis results were similar to previous reports exhibiting structural changes and erosions on the surface of LDPE films in terms of porosity, cavities, holes, scions, and cracks by consortia of some fungi such as Aspergillus and Penicillium [40,61]. The surface of LDPE films obtained from culturing with these fungal cultures was changed from smooth to holes with cracks, and a decrease in molecular weight and an increase in carbonyl double bond groups caused by the fungi were also observed.

VOCs emitted from LDPE films culturing with potential fungi were identified using GC-MS. Most VOCs in all extracts were major hydrocarbons originated from polymer chains in LDPE films with functional groups of $\mathrm{C}-\mathrm{O}-\mathrm{C}$ and $-\mathrm{C}=\mathrm{C}$ - detected from the FTIR analysis. These compounds might be produced from oligomers generated during the LDPE polymerization [35]. These VOCs may be produced from multiple pathways, including the primary, secondary and tertiary radicals [62]. In addition, some VOCs with oxygen-containing compounds might be generated from oxidation degradation of LDPE during incubation [63]. The degradation of LDPE chain by each fungus was dependent on degradation processes with different multiple active sites of the catalyst or mechanical degradation products [63]. The results show that the degradation of LDPE films by different fungi produce particular VOC emissions, the levels of these emissions have been demonstrated to change with increased degradation. Analysis of these VOCs showed evidence of degradation and enabled degradation progress to be monitored. VOC analysis could lead to improved condition assessment and monitoring of degradation of a LDPE films. However, mechanisms responsible for VOC emission from polymers are unknown.

The fungi collected from Thailand were successful in degrading LDPE films under laboratory conditions, especially C. fructicola. Their effectiveness in the degradation of LDPE films by culturing was investigated over an incubation period of 90 days. It is noted that releasing of $\mathrm{CO}_{2}$ and enzyme production by potential fungi lead to higher LDPE degradation values. In addition, FTIR analysis showed the formation of carbonyl groups, $\mathrm{CH}$ stress, and $\mathrm{CH}_{2}$ groups. CI index from FTIR analysis was decreased after culturing with fungi. These decreasing values are due to the consumption of carbonyl and carboxylic acid derivatives by fungi, indicating the depolymerization of the polymeric chain. Analysis through SEM and GC-MS also confirmed the degradation of LDPE films, showing the presence of erosion and fragility of the LDPE film surface. The degradation mechanism may be attributed to enzyme production by fungal actions. Therefore, the obtained information can be used as evidence for the degradation potential of the fungi on LDPE films which can be further applied at an industrial scale for degrading various plastic materials.

However, there is limited information about the optimum conditions, such as incubation period, temperature, humidity, inorganic medium and $\mathrm{pH}$, for culturing potential fungi. In addition, the determination of toxicity level after culturing is also necessary before using them as a biodegradable fungus.

Author Contributions: S.K. and T.S. performed the experiments. S.K. performed the data analysis and interpretation. S.K. also wrote the main manuscript text and prepared figures. P.P. and S.K. reviewed the manuscript. P.P. supervised the work and edited the manuscript. All authors have read and agreed to the published version of the manuscript.

Funding: This research was funded by the Mae Fah Luang University grant and the Royal Golden Jubilee Ph.D. Programme through grant no. PHD/0193/2560.

Institutional Review Board Statement: Not applicable.

Informed Consent Statement: Not applicable.

Data Availability Statement: Not applicable.

Acknowledgments: The authors are grateful to the Center of Excellence in Fungal Research, Mae Fah Luang University for providing all fungi in this study. 
Conflicts of Interest: The authors declare no conflict of interest.

\section{References}

1. Caruso, G. Plastic degrading microorganisms as a tool for bioremediation of plastic contamination in aquatic environments. $J$. Pollut. Eff. Cont. 2015, 3, 1000e112. [CrossRef]

2. Roy, P.K.; Titus, S.; Surekha, P.; Tulsi, E.; Deshmukh, C.; Rajagopal, C. Degradation of abiotically aged LDPE films containing pro-oxidant by bacterial consortium. Polym. Degrad. Stab. 2008, 93, 1917-1922. [CrossRef]

3. Pollution Control Department. Thailand Pollution Report 2018, 1st ed.; Pollution Control Department: Bangkok, Thailand, 2018.

4. Kyaw, B.M.; Champakalakshmi, R.; Sakharkar, M.K.; Lim, C.S.; Sakharkar, K.R. Biodegradation of low density polythene (LDPE) by Pseudomonas species. Indian J. Microbiol. 2012, 52, 411-419. [CrossRef]

5. Gajendiran, A.; Krishnamoorthy, S.; Abraham, J. Microbial degradation of low-density polyethylene (LDPE) by Aspergillus clavatus strain JASK1 isolated from landfill soil. 3Biotech 2016, 6, 52. [CrossRef]

6. Moore, C.J. Synthetic polymers in the marine environment: A rapidly increasing, long-term threat. Environ. Res. 2008, 108, 131-139. [CrossRef]

7. Derraik, J.G.B. The pollution of the marine environment by plastic debris: A review. Mar. Pollut. Bull. 2002, 44, 842-852. [CrossRef]

8. Starnes, J.R.W.H. Structural and mechanistic aspects of the thermal degradation of poly (vinyl chloride). Prog. Polym. Sci. 2002, 27, 2133-2170. [CrossRef]

9. Mahalakshmi, V.; Siddiq, A.; Andrew, S.N. Analysis of polyethylene degrading potentials of microorganisms isolated from compost soil. Int. J. Pharm. Biol. Arch. 2012, 31, 190-1196.

10. Sangale, M.K.; Shahnawaz, M.; Ade, A.B. A review on biodegradation of polythene: The microbial approach. J. Bioremediat. Biodegrad. 2012, 3, 1-9. [CrossRef]

11. Singh, B. Harmful effect of plastic in animals. Indian Cow. Sci. Econ. J. 2005, 2, 10-18.

12. Muthukumar, A.; Veerappapillai, S. Biodegradation of plastics: A brief review. Int. J. Pharm. Sci. Rev. Res. 2015, 31, 204-209. [CrossRef]

13. Kasirajan, S.; Ngouajio, M. Polyethylene and biodegradable mulches for agricultural applications: A review. Agron. Sustain. Dev. 2012, 32, 501-529. [CrossRef]

14. Wang, J.; Liu, X.; Li, Y.; Powell, T.; Wang, X.; Wang, G.; Zhang, P. Microplastics as contaminants in the soil environment: A mini-review. Sci. Total Environ. 2019, 691, 848-857. [CrossRef]

15. Zettler, E.R.; Mincer, T.J.; Amaral-Zettler, L.A. Life in the "plastisphere": Microbial communities on plastic marine debris. Environ. Sci. Technol. 2013, 47, 7137-7146. [CrossRef] [PubMed]

16. Bryant, J.A.; Clemente, T.M.; Viviani, D.A.; Fong, A.A.; Thomas, K.A.; Kemp, P.; Karl, D.M.; White, A.E.; DeLong, E.F. Diversity and activity of communities inhabiting plastic debris in the North Pacific Gyre. mSystems 2016, 1, e00024-16. [CrossRef] [PubMed]

17. Sumathi, T.; Viswanath, B.; Sri Lakshmi, A.; SaiGopal, D.V. Production of laccase by Cochliobolus sp. isolated from plastic dumped soils and their ability to degrade low molecular weight PVC. Biochem. Res. Int. 2016, 9519527. [CrossRef]

18. Sheik, S.; Chandrashekar, K.R.; Swaroop, K.; Somashekarappa, H.M. Biodegradation of gamma irradiated low density polyethylene and polypropylene by endophytic fungi. Int. Biodeterior. Biodegr. 2015, 105, 21-29. [CrossRef]

19. Gu, J.D.; Ford, T.E.; Mitchell, R. Microbiological corrosion of concrete. In Uhlig's Corrosion Handbook, 2nd ed.; John Wiley \& Sons: Hoboken, NJ, USA, 2011; pp. 477-491.

20. Suman, M.; Shamba, C. A comparative study of commercially available plastic carry bag biodegradation by microorganisms isolated from hydrocarbon effluent enriched soil. Int. J. Curr. Microbiol. Appl. Sci. 2014, 3, 318-325.

21. Konduri, M.K.; Anupam, K.S.; Vivek, J.S.; Kumar, D.B.R.; Narasu, M.L. Synergistic effect of chemical and photo treatment on the rate of biodegradation of high density polyethylene by indigenous fungal isolates. Int. J. Biotechnol. Biochem. 2010, 6, 157-175.

22. Constantin, M.; Iuliana, R.; Vasilescu, G.; Arsene, M.L.; Luiza, J. Colonization and degradation of polyethylene composites by fungal strains isolated. Sci. Bull. Ser. F Biotechnol. 2012, 16, 109-112.

23. Sowmya, H.V.; Ramalingappa, B.; Nayanashree, G.; Thippeswamy, B.; Krishnappa, M. Polyethylene degradation by fungal consortium. Int. J. Env. Res. 2015, 9, 823-830.

24. Ojha, N.; Pradhan, N.; Singh, S.; Barla, A.; Shrivastava, A.; Khatua, P.; Rai, V.; Bose, S. Evaluation of HDPE and LDPE degradation by fungus, implemented by statistical optimization. Sci. Rep. 2017, 7, 39515. [CrossRef]

25. Ezziyyani, M.; Requena, M.E.; Egea-Gilabert, C.; Candela, M.E. Biological control of phytophthora root rot of pepper using Trichoderma harzianum and Streptomyces rochei in combination. Phytopathology 2007, 155, 342-349. [CrossRef]

26. Hyde, K.D.; Norphanphoun, C.; Chen, J.; Dissanayake, A.J.; Doilom, M.; Hongsanan, S.; Jayawardena, R.S.; Jeewon, R.; Perera, R.H.; Thongbai, B.; et al. Thailand's amazing diversity: Up to $96 \%$ of fungi in northern Thailand may be novel. Fungal Divers. 2018, 93, 215-239. [CrossRef]

27. Pinnoi, A.; Pinuran, U.; Hyde, K.D.; McKenzie, E.H.C.; Lumyong, S. Submersisphaeria palmae sp. nov. with a key to species, and notes on Helicoubisia. Sydowia 2004, 56, 72-78.

28. Thongkantha, S.; Lumyong, S.; McKenzie, E.H.C.; Hyde, K.D. Fungal saprobes and pathogens occurring on tissues of Dracaena lourieri and Pandanus spp. in Thailand. Fungal Divers. 2008, 30, 149-169. 
29. Passos, T.M.; Marconato, J.C.; Franchetti, S.M. Biodegradation of films of low density polyethylene (LDPE), poly(hydroxibutyrateco-valerate) (PHBV), and LDPE/PHBV (70/30) blend with Paecilomyces variotii. Polimeros 2015, 25, 29-34. [CrossRef]

30. Brunner, I.; Fischer, M.; Rüthi, J.; Stierli, B.; Frey, B. Ability of fungi isolated from plastic debris floating in the shoreline of a lake to degrade plastics. PLoS ONE 2018, 13, e0202047. [CrossRef] [PubMed]

31. Ameen, F.; Moslem, M.; Hadi, S.; Al-Sabri, A.E. Biodegradation of Low Density Polyethylene (LDPE) by Mangrove fungi from the red sea coast. Prog. Rubber Plast. Recycl. Technol. 2015, 31, 125-143. [CrossRef]

32. Orr, I.G.; Hadar, Y.; Sivan, A. Colonization, biofilm formation and biodegradation of polyethylene by a strain of Rhodococcus ruber. Appl. Microbiol. Biotechnol. 2004, 65, 97-104. [CrossRef]

33. Amjadi, M.; Ali, F.; Amjadi, M.; Fatemi, A. Tensile behavior of high-density polyethylene including the effects of processing technique, thickness, temperature, and strain rate. Polymers 2020, 12, 1857. [CrossRef] [PubMed]

34. Almond, J.; Sugumaar, P.; Wenzel, M.N.; Hill, G.; Wallis, C. Determination of the carbonyl index of polyethylene and polypropylene using specified area under band methodology with ATR-FTIR spectroscopy. e-Polymers 2020, 20, 369-381. [CrossRef]

35. Park, S.Y.; Kim, C.G. Biodegradation of micro-polyethylene particles by bacterial colonization of a mixed microbial consortium isolated from a landfill site. Chemosphere 2019, 222, 527-533. [CrossRef]

36. Hyde, K.D.; Xu, J.; Rapior, S.; Jeewon, R.; Lumyong, S.; Niego, A.G.; Abeywickrama, P.D.; Aluthmuhandiram, J.V.; Brahamanage, R.S.; Brooks, S.; et al. The amazing potential of fungi: 50 ways we can exploit fungi industrially. Fungal Divers. 2019, 97, 1-136. [CrossRef]

37. Manamgoda, D.S.; Udayanga, D.; Cai, L.; Chukeatirote, E.; Hyde, K.D. Endophytic Colletotrichum from tropical grasses with a new species C. endophytica. Fungal Divers. 2013, 61, 107-115. [CrossRef]

38. Hyde, K.D.; Tennakoon, D.S.; Jeewon, R.; Bhat, D.J.; Maharachchikumbura, S.S.; Rossi, W.; Leonardi, M.; Lee, H.B.; Mun, H.Y.; Houbraken, J.; et al. Fungal diversity notes 929-1035: Taxonomic and phylogenetic contributions on genera and species of fungal taxa. Fungal Divers. 2019, 96, 1-242. [CrossRef]

39. Nevalainen, H.; Kautto, L.; Te'o, V. Methods for isolation and cultivation of filamentous fungi. In Methods in Molecular Biology; Humana Press: Totowa, NJ, USA, 2014; pp. 3-16. [CrossRef]

40. Volke-Sepúlveda, T.; Saucedo-Castañeda, G.; Gutiérrez-Rojas, M.; Manzur, A.; Favela-Torres, E. Thermally treated low density polyethylene biodegradation by Penicillium pinophilum and Aspergillus niger. J. Appl. Polym. Sci. 2002, 83, 305-314. [CrossRef]

41. Shabani, F.; Kumar, L.; Esmaeili, A. A modelling implementation of climate change on biodegradation of Low-Density Polyethylene (LDPE) by Aspergillus niger in soil. Glob. Ecol. Conserv. 2015, 4, 388-398. [CrossRef]

42. Esmaeili, A.; Pourbabaee, A.A.; Alikhani, H.A.; Shabani, F.; Esmaeili, E. Biodegradation of low-density polyethylene (LDPE) by mixed culture of Lysinibacillus xylanilyticus and Aspergillus niger in soil. PLoS ONE 2013, 8, e71720. [CrossRef]

43. Manzur, A.; Limón-González, M.; Favela-Torres, E. Biodegradation of physicochemically treated LDPE by a consortium of filamentous fungi. J. Appl. Polym. Sci. 2004, 92, 265-271. [CrossRef]

44. Panagiotidou, E.; Konidaris, C.; Baklavaridis, A.; Zuburtikudis, I.; Achilias, D.; Mitlianga, P.A. Simple route for purifying extracellular poly (3-hydroxybutyrate)-depolymerase from Penicillium pinophilum. Enzym. Res. 2014, 159809. [CrossRef]

45. Sowmya, H.V.; Krishnappa, M. Degradation of polyethylene by Penicillium simplicissimum isolated from local dumpsite of Shivamogga district. Environ. Dev. Sustain. 2015, 17, 731-745. [CrossRef]

46. Cavello, I.A.; Cavalitto, S.F.; Hours, R.A. Biodegradation of a keratin waste and the concomitant production of detergent stable serine proteases from Paecilomyces lilacinus. Appl. Biochem. Biotechnol. 2012, 167, 945-958. [CrossRef] [PubMed]

47. Camilo, S.B.; Ono, C.J.; Ueno, Y.; Hirooka, E.Y. Anti-Fusarium moniliforme activity and fumonisin biodegradation by corn and silage microflora. Braz. Arch. Biol. Technol. 2000, 43, 159-164. [CrossRef]

48. Gu, J.D. Microbial colonization of polymeric materials for space applications and mechanisms of biodeterioration: A review. Int. Biodeterior. Biodegr. 2007, 59, 170-179. [CrossRef]

49. Webb, J.S.; Nixon, M.; Eastwood, I.M.; Greenhalgh, M.; Robson, G.D.; Handley, P.S. Fungal colonization and Biodeterioration of plasticized polyvinylchloride. Appl. Environ. Microbiol. 2000, 66, 3194-3200. [CrossRef]

50. Pramila, R.; Ramesh, K.V. Biodegradation of low-density polyethylene (LDPE) by fungi isolated from marine water-A SEM analysis. Afr. J. Microbiol. Res. 2011, 5, 5013-5018. [CrossRef]

51. Shah, A.; Hasan, F.; Hameed, A.; Akhter, J. Isolation of Fusarium sp. AF4 from sewage sludge, with the ability to adhere the surface of polyethylene. Afr. J. Microbiol. Res. 2009, 3, 658-663.

52. Sanin, S.L.; Sanin, F.D.; Bryers, J.D. Effect of starvation on the adhesive properties of xenobiotic degrading bacteria. Process Biochem. 2003, 38, 909-914. [CrossRef]

53. Vijaya, C.; Reddy, R.M. Impact of soil composting using municipal solid waste on biodegradation of plastics. Indian J. Biotechnol. 2008, 7, 235-239.

54. Corti, A.; Muniyasamy, S.; Vitali, M.; Imam, S.H.; Chiellini, E. Oxidation and biodegradation of polyethylene films containing pro-oxidant additives: Synergistic effects of sunlight exposure, thermal aging and fungal biodegradation. Polym. Degrad. Stab. 2010, 95, 1106-1114. [CrossRef]

55. Usha, R.; Sangeetha, T.; Palaniswamy, M. Screening of polyethylene degrading microorganisms from garbage soil. LARCJI 2011, 2, 200-204. [CrossRef]

56. Sudhakar, M.; Doble, M.; Murthy, P.S.; Venkatesan, R. Marine microbe-mediated biodegradation of low-and high-density polyethylenes. Int. Biodeterior. Biodegr. 2008, 61, 203-213. [CrossRef] 
57. Bhatia, M.; Girdhar, A.; Tiwari, A.; Nayarisseri, A. Implications of a novel Pseudomonas species on low density polyethylene biodegradation: An in vitro to in silico approach. SpringerPlus 2014, 3, 497. [CrossRef] [PubMed]

58. Rivard, C.; Moens, L.; Roberts, K.; Brigham, J.; Kelley, S. Starch esters as biodegradable plastics: Effects of ester group chain length and degree of substitution on anaerobic biodegradation. Enzym. Microb. Technol. 1995, 17, 848-852. [CrossRef]

59. Ratanakamnuan, U.; Aht-Ong, D. Photobiodegradation of low-density polyethylene/banana starch films. Appl. Polym. Sci. 2006, 100, 2725-2736. [CrossRef]

60. Pathak, V.M. Review on the current status of polymer degradation: A microbial approach. Bioresour. Bioprocess 2017, 4, 15. [CrossRef]

61. Das, M.P.; Kumar, S. Microbial deterioration of low density polyethylene by Aspergillus and Fusarium sp. Int. J. Chemtech. Res. 2014, 6, 299-305.

62. Francois-Heude, A.; Richaud, E.; LeProvost, J.; Heninger, M.; Mestdagh, H.; Desnoux, E.; Colin, X. Real-time quantitative analysis of volatile products generated during solid-state polypropylene thermal oxidation. Polym. Test. 2013, 32, 907-917. [CrossRef]

63. Kang, P.; Wu, P.; Jin, Y.; Shi, S.; Gao, D.; Chen, G.; Li, Q. Formation and emissions of volatile organic compounds from homo-PP and co-PP resins during manufacturing process and accelerated photoaging degradation. Molecules 2020, 25, 2761. [CrossRef] [PubMed] 